\title{
Mapping Geological Structures Controlling Mineralization in Enyigba Area, South Eastern Nigeria, using Magnetic Inversion Technique
}

\author{
Ema M. Abraham*, Daniel A. Mbarah, Ndidiamaka N. Eluwa \\ Department of Physics/Geology/Geophysics, Federal University Ndufu Alike Ikwo, P.M.B. 1010 Abakaliki, \\ Ebonyi State, Nigeria
}

*Corresponding Author: Ema M. Abraham, Department of Physics/Geology/Geophysics, Federal University Ndufu Alike Ikwo, P.M.B. 1010 Abakaliki, Ebonyi State, Nigeria.

\begin{abstract}
Magnetic Inversion (MI) and Analytic Signal techniques were applied to map geological structures controlling mineralisation in Enyigba area of Ebonyi State. Forward modelling technique was employed in the quantitative interpretations to determine magnetic susceptibilities and type of mineralisation prevalent in the study region. High resolution aeromagnetic data acquired from Nigerian Geological Survey Agency was used in this study. The Analytic Signal technique was applied to independently verify results obtained from the MI modeling. 3D inversions results have revealed the existence of subsurface intrusions within the Enyigba region when contrasted with the background geology of shale. Geologically the shale is generally weathered, fissile, thinly laminated and highly fractured, varies between greyish brown to dark grey in colour and holds a general magnetic property. Analytic Signal result effectively confirms results from MI by retracing the regions of the intrusions. These mapped intrusive were interpreted as representative of the various mineral deposits in the region, some of which were identified as Lead-Zinc mineralization currently being mined in the region. Other intrusive within the coverage area could point to extended possibilities of other mineral forms yet to be mined. This study has provided additional insights to locations of mineral intrusions yet to be identified by local miners in the region. Sites with higher yield potentials have also been identified for further investigations using other geological/geophysical techniques. The outcome would aid efficient mineral mining in the region.
\end{abstract}

Keywords: Magnetics, Analytic Signal, Minerals, Mining, Intrusions, Enyigba, Nigeria

\section{INTRODUCTION}

Enyigba is located within Ikwo and Abakaliki Local Government Areas of Ebonyi State on latitudes $6^{\circ} 09^{\prime} \mathrm{N}$ and $6^{\circ} 14^{\prime} \mathrm{N}$ and longitude $8^{\circ} 05^{\prime} \mathrm{E}$ and $8^{\circ} 10^{\prime} \mathrm{E}$ (Figure 1) and falls within the lower Benue sedimentary formation of southeastern Nigeria. The region is noted for Lead-Zinc mineral $(\mathrm{Pb} / \mathrm{Zn})$ mining activities by the locals. $\mathrm{Pb} / \mathrm{Zn}$ deposits have been found in the lower Abakaliki Basin where metallic ores occur as epigenetic fracture controlled vein deposits, and are restricted to gently dipping carbonaceous black shale spatially distributed (Fatoye et al., 2014). Cratheley and Jones (1965) had earlier attempted to map possible trends of these deposits within the entire Benue Trough (Figure 2). They noted that the outcrops are exposed by road cuts, some agricultural activities, mine sites, and streams/River channels and covered about $54.56 \mathrm{~km}^{2}$. The cretaceous sequence of the lower Benue Trough consists of shale, limestone, minor intrusions and pyroclastics and belongs to the Asu River geologic group of Albian age. These are the earliest sediments that were deposited uncomfortably on subsiding basement topographical depression in the Benue basin (Burke et al., 1970).

$\mathrm{Pb}-\mathrm{Zn}$ occurrences in Nigeria are associated with saline water intrusion in the sedimentary basins or fractured/shear zones in crystalline rocks. The mineralisation is often associated with minor to significant amounts of copper and silver, occurring in lodes filing the fractures within the sedimentary rocks in the Benue Trough. There is also the presence of Volcanic and Pyroclastic materials forming elongated conical hills in the cores of the anticlinal structures of the lower Benue Trough. The Abakaliki lead-zinc mineralization is believed to be of hydrothermal origin emplaced at a low temperature of about $1400^{\circ} \mathrm{C}$ and it is made up of primarily four lodes namely Ishiagu, Enyigba, Ameri, Ameka in the lower Benue Trough (Kaliberng, 2011). 
Mapping Geological Structures Controlling Mineralization in Enyigba Area, South Eastern Nigeria, using Magnetic Inversion Technique

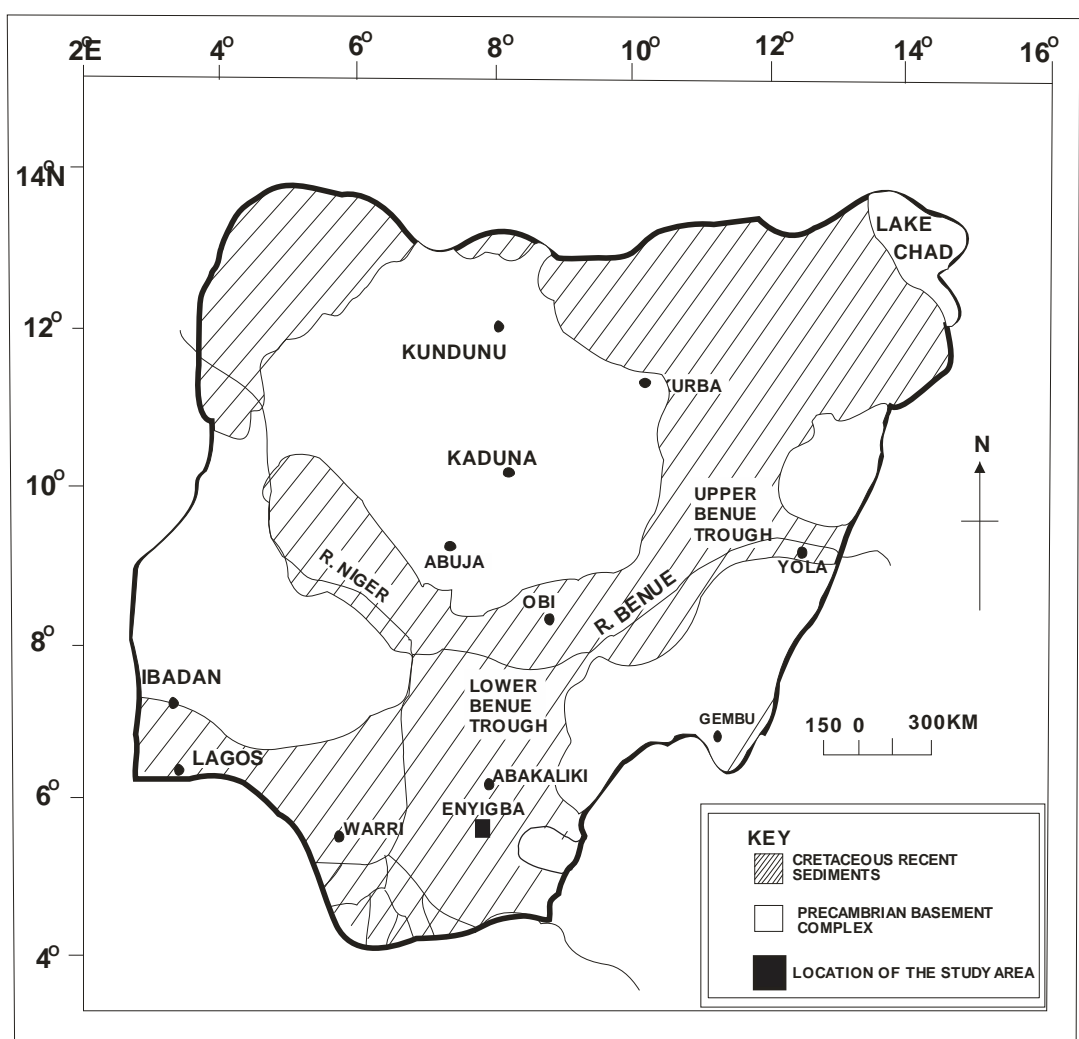

Figure1. Map of Nigeria displaying the general geology. The study area (Enyigba) is located at the south eastern region of the map (Modified from Abraham et al., 2014).

The Enyigba lode which appears to be the largest mineralized body in the lower Benue Trough section is estimated at $2 \mathrm{~km}$ in Length and has a width of approximately $30 \mathrm{~m}$. It occurs as open vein fillings of a series of steeply dipping N-S near vertical fault, cutting regional folds of Abakaliki Anticlinorium. The lode also extends southwards into Ameri lode.

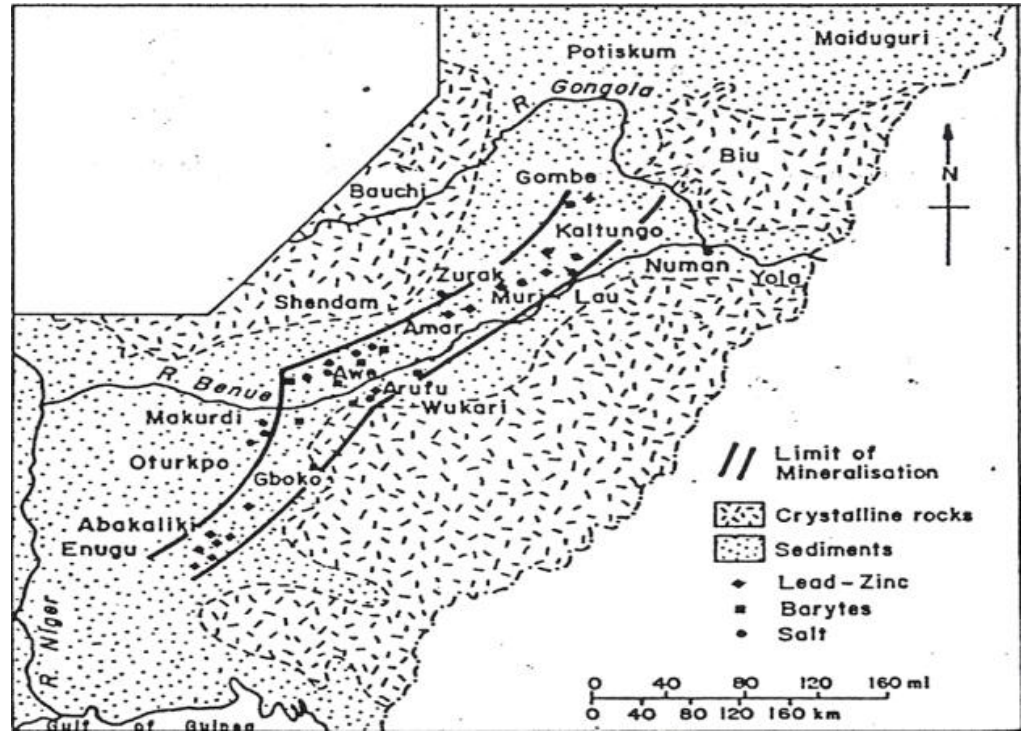

Figure2. Map of the Benue Trough showing locations of ore mineralization (Cratheley and Jones, 1965)

Current mining activities takes only place along the hydrothermal $\mathrm{Pb}-\mathrm{Zn}$ vein mineralisation sections of the whole landscape. This occupies about $10 \%$ of the study area and comprises of vein ridges and low-lying mineralization terrains. The mode of mineralization of Enyigba lode according to Orazulike (1994) was largely by open space filling. Uzuakpunwa (1974) held that the tectonic history of the Abakaliki district shows there was extensive faulting, folding with igneous activities and mineralization. Macro textures on the minerals include incompletely filled cavities in mineralized zone. At present, no documented geophysical investigation presenting the subsurface distribution of 
Mapping Geological Structures Controlling Mineralization in Enyigba Area, South Eastern Nigeria, using Magnetic Inversion Technique

the mineral deposits at Enyigba have been conducted. As a result, it becomes practically challenging to determine with accuracy the subsurface extent of these lodes. Mining activities in the region are indiscriminate and executed by the locals once a vein has been discovered on the surface. Figure 3 show an image of one of the mined sites. Our study adopts a pioneering approach towards evaluating the structural setup of these mineral deposits at Enyigba using the magnetic inversion techniques. A high resolution aeromagnetic data would be processed/analysed to examine in three-dimension (3D) the mineral structures within the study area. We believe that results from our study would provide a reliable estimate of the various mineral deposits as well as their locations within the region. This would allow miners to be properly guided on the location of these deposits and their potential yield.

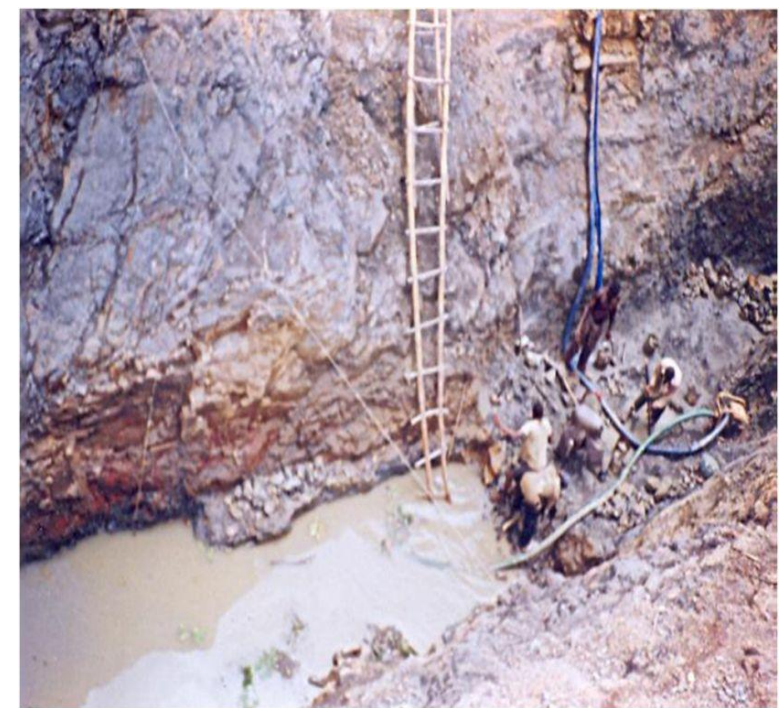

Figure3. One of the open cast mine sites currently exploited by the locals.

Inversion technique solves the challenge of varying direction of rock magnetization to provide a more reliable representation of subsurface geology, thereby gaining greater insight in the interpretation of magnetic data. 3D inversion is fast becoming part of a standard geophysical exploration workflow. Conventional inversion of Total Magnetic Intensity (TMI) data recovers the susceptibility as the preferred rock property.

\section{METHOD}

High resolution aeromagnetic data of the region was obtained from the Nigerian Geological Survey Agency, (NGSA) on the Abakaliki sheet 303. Data was acquired by the agency using a mean terrain clearance of $80 \mathrm{~m}$ and $500 \mathrm{~m}$ line spacing. The geomagnetic gradient was removed from the data using the International Geomagnetic Reference Field (IGRF) formula of 2005. Figure 4 display the Abakaliki sheet 303 aeromagnetic anomaly map with some of the mines locations plotted in.
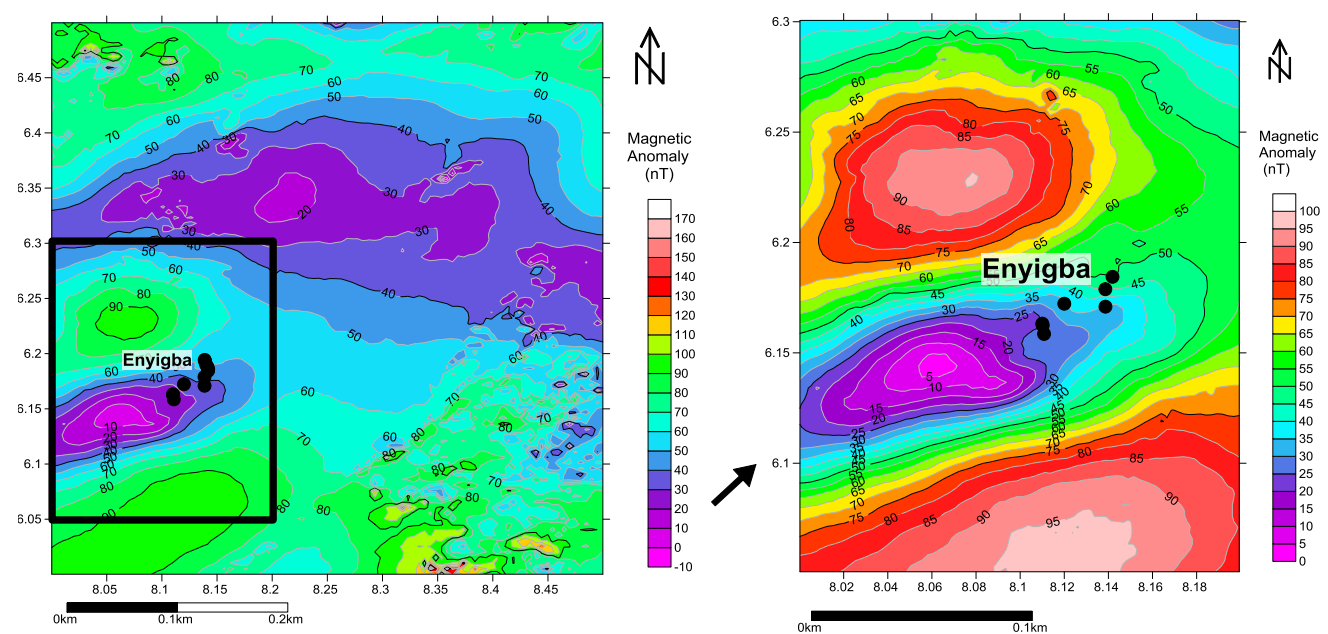

Figure4. Residual total magnetic anomaly map of the region. The map representation on the right is a blow-out of the study region from the left. Current mine locations have been plotted as black dots. 
Mapping Geological Structures Controlling Mineralization in Enyigba Area, South Eastern Nigeria, using Magnetic Inversion Technique

The aeromagnetic map displays basically short wavelength anomalies at the Enyigba region with negative anomalies. We suspect that the deposited minerals, notably $\mathrm{NaCl}$ and $\mathrm{Pb}-\mathrm{Zn}$ deposits in the region could be responsible for the negative susceptibilities recorded. This region is particularly surrounded by positive magnetic anomalies reaching values as high as $110 \mathrm{nT}$.

Pilkington (2009) developed a 3D magnetic data-space inversion with sparseness constraints and tested his approach on aeromagnetic data collected over a Precambrian Shield area. His results show that including the sparseness constraint lead to a simpler and better resolved solution. Tests on synthetic data show that sparse inversion produces a much more focused solution compared with a standard model-space, least squares inversion. Therefore we adopted the method of Pilkington (2009) for our 3D inversion modelling study. The method presenting a linear forward problem relating the dipole susceptibilities $m$ to the magnetic field $d(N X \times N Y=N)$ can be written concisely in the matrix form as

$\mathrm{d}=\mathrm{Am}$

Where the elements of $\mathbf{A}, a_{i j}$, represent the effect of unit susceptibility of dipole $j(j=1, \ldots, M)$ at data location $(\mathrm{I}=1, \ldots, \mathrm{N})$. Use of equation (1) implies that no remanent magnetization is present and that the inducing field direction is constant throughout the model domain.

To confirm whether the magnetic anomalies within the area of study were caused by intrusions, we computed the analytic signal response of the geomagnetic field of the area. The Analytic Signal (AS) is given by (Roest et al., 1992; Riedel, 2008):

$\mathrm{A}(\mathrm{x}, \mathrm{y})=\sqrt{\left(\frac{\partial \mathrm{T}}{\partial \mathrm{x}}\right)^{2}+\left(\frac{\partial \mathrm{T}}{\partial \mathrm{y}}\right)^{2}+\left(\frac{\partial \mathrm{T}}{\partial \mathrm{z}}\right)^{2}}$

Where $\mathrm{T}$ is the observed field at $\mathrm{x}$ and $\mathrm{y}$.

While this function is not a measurable parameter, it is extremely interesting in the context of interpretation, as it is completely independent of the direction of magnetization and the direction of the inducing field. This means that all bodies with the same geometry have the same analytic signal. This signal exhibits maxima over magnetization contrasts, independent of the ambient magnetic field and source magnetization directions. Locations of these maxima thus determine the outlines of magnetic sources. The analytic signal is useful in locating the edges of the magnetic source bodies, particularly where remanance, and/or low magnetic latitude (as in this study region) may complicate interpretation (Whitehead and Musselman, 2005).

\section{RESULTS AND DISCUSSION}

We present results from our analysis of the aeromagnetic data using inversion techniques. Figure 5 displays the final 3D results of the subsurface structures at the Enyigba region. This was obtained after clipping the background susceptibility of the Initial model result realized from Magnetic Inversion modelling.

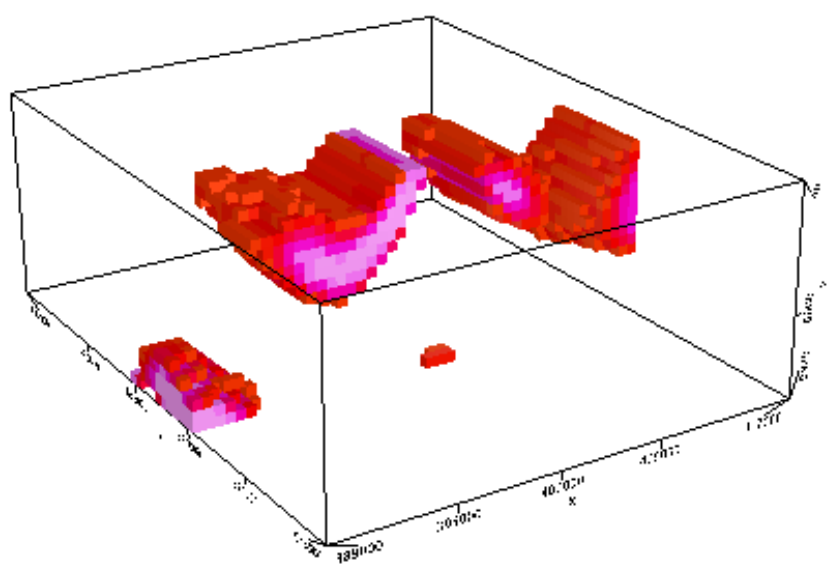

Figure5. Final modelling results obtained by clipping the background susceptibilities of the initial model. Clearly distinguished intrusions could be seen in the model results. 
Mapping Geological Structures Controlling Mineralization in Enyigba Area, South Eastern Nigeria, using Magnetic Inversion Technique

The model results indicates that the various contrasting minerals in the region could be reached at depths less that $400 \mathrm{~m}$ and extends as deep as $5000 \mathrm{~m}$ below the subsurface. To better understand the distribution of the mapped 3D intrusions, we overlay the 2D aeromagnetic anomaly map used in the study on the model results (Figure 6). Recall that the region of low magnetic anomalies in the mapped was traced to the Enyigba locality. Figure 6 confirms the possible mineral deposits at the location. We proposed that the mapped deposits underlying the Enyigba region are mineral deposits which may convincingly represent the currently mined $\mathrm{Pb}-\mathrm{Zn}$ deposits.

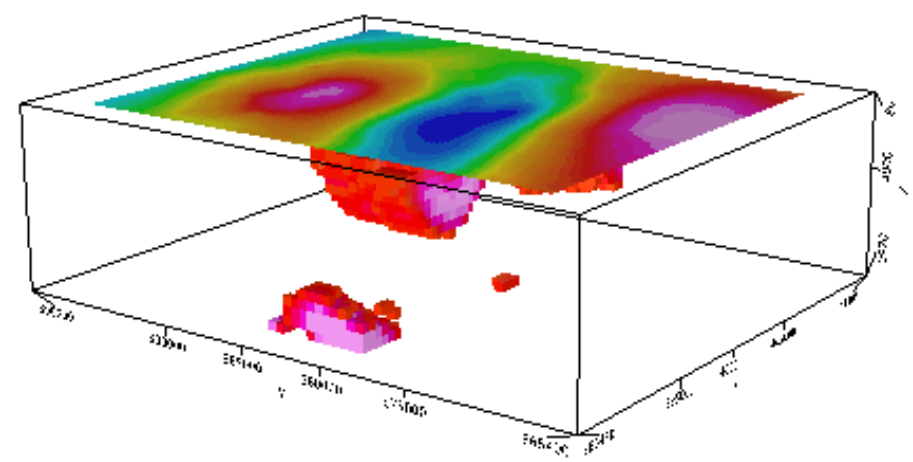

Figure6. 2D magnetic data overlain on the $3 D$ inversion results.

Figure 7 displays the 3D representation of the magnetic anomaly data on the model results from multiple angles. (a), (b), (c), and (d) represents different orientation of the model result. This was performed to allow multiple assessment of the model and perform effective comparison of the degree of reconciliation with the anomaly data. Again results clearly show sizable mineral deposits especially at the Enyigba location. We also observed a massive deposition away from the active mine sites in the area. This indicates a massive reserve in the region yet to be exploited.

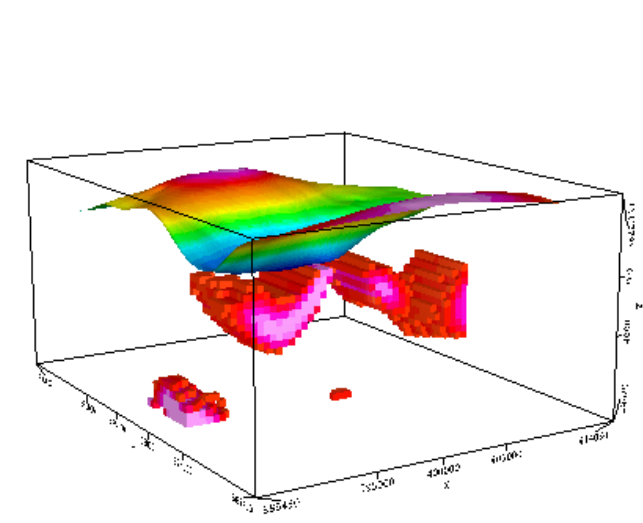

(a)

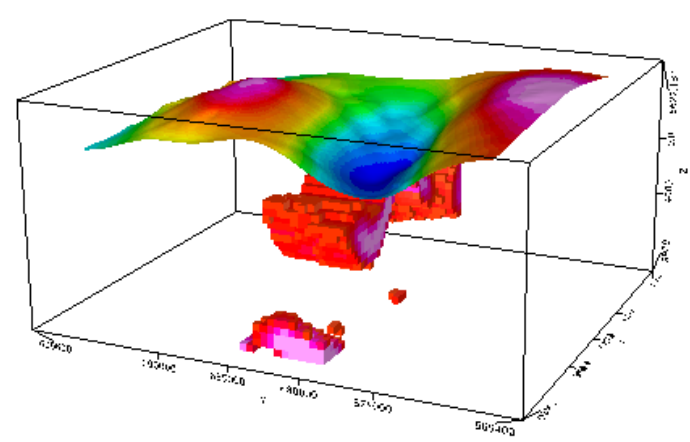

(c)

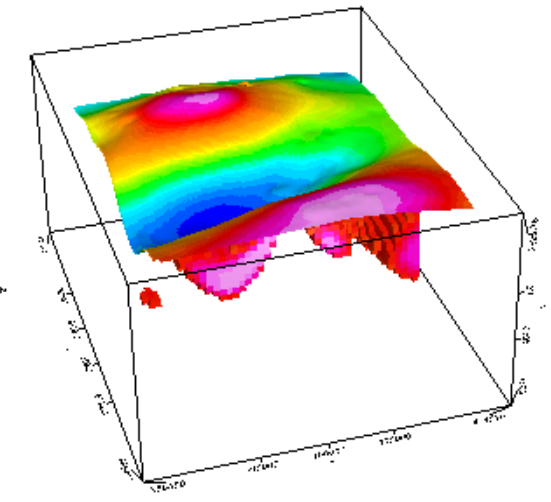

(b)

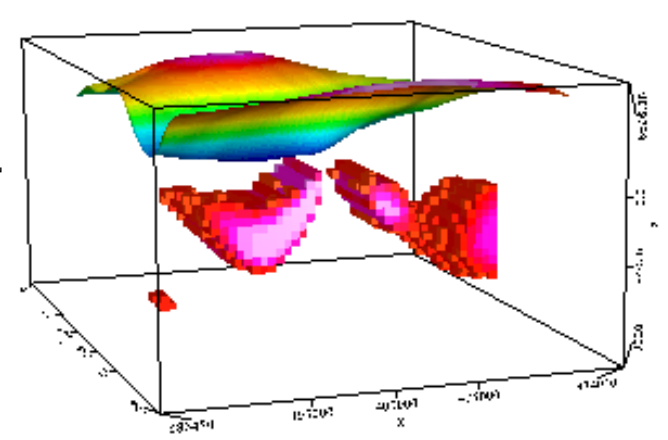

(d)

Figure7. 3D inversion results with $3 D$ magnetic data viewed from different angles $(a, b, c, d, e)$. It could be seen that the geologic intrusions in the model concentrates around the Enyigba location.

To consider the relationship between the subsurface intrusions and the topography of the region, we plotted a 3D representation of the model results and topographic data. The analysis is presented in 
Mapping Geological Structures Controlling Mineralization in Enyigba Area, South Eastern Nigeria, using Magnetic Inversion Technique

Figure 8. We observed a rise in the topography within the region of subsurface deposits and a decrease at locations devoid of subsurface mineral deposition in our model results.

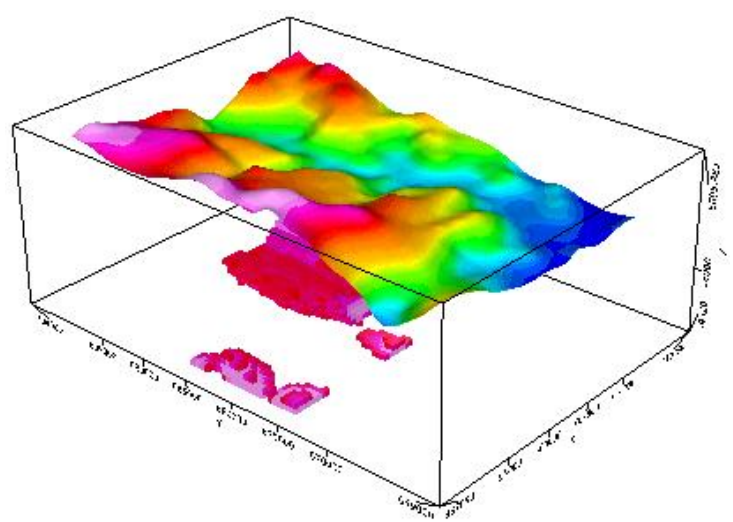

(a)

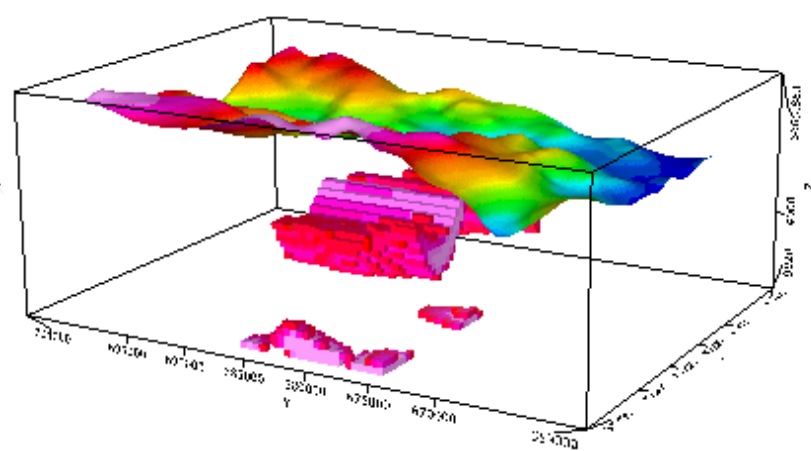

(b)

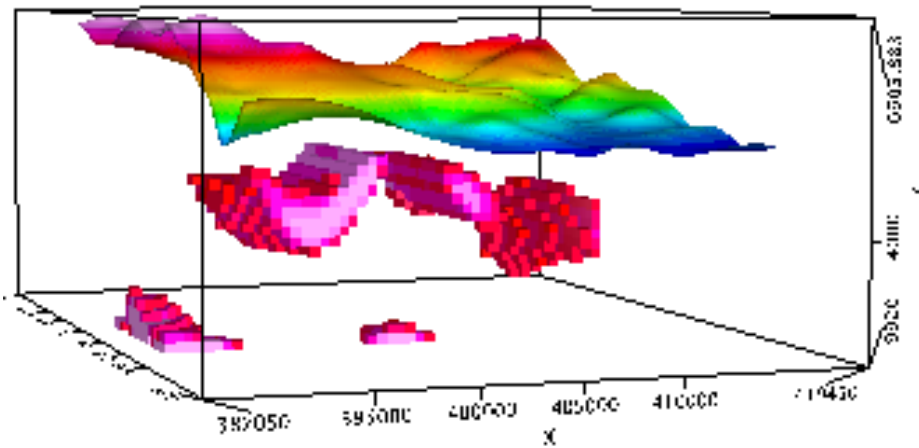

(c)

Figure8. 3D inversion results with $3 D$ DEM data viewed from different angles $(a, b, c)$. It could be seen that the geologic intrusions in the model concentrates around the Enyigba location with increased elevation.

A combine representation of the magnetic anomaly data used for this study and the Digital Elevation Model (DEM) data was performed to observed their combined interactions as regards the model results. Figure 9 displays result of this plot. We observed that the intrusion at Enyigba region was responsible for the anomaly effects on both the magnetic and topographic data from the region.

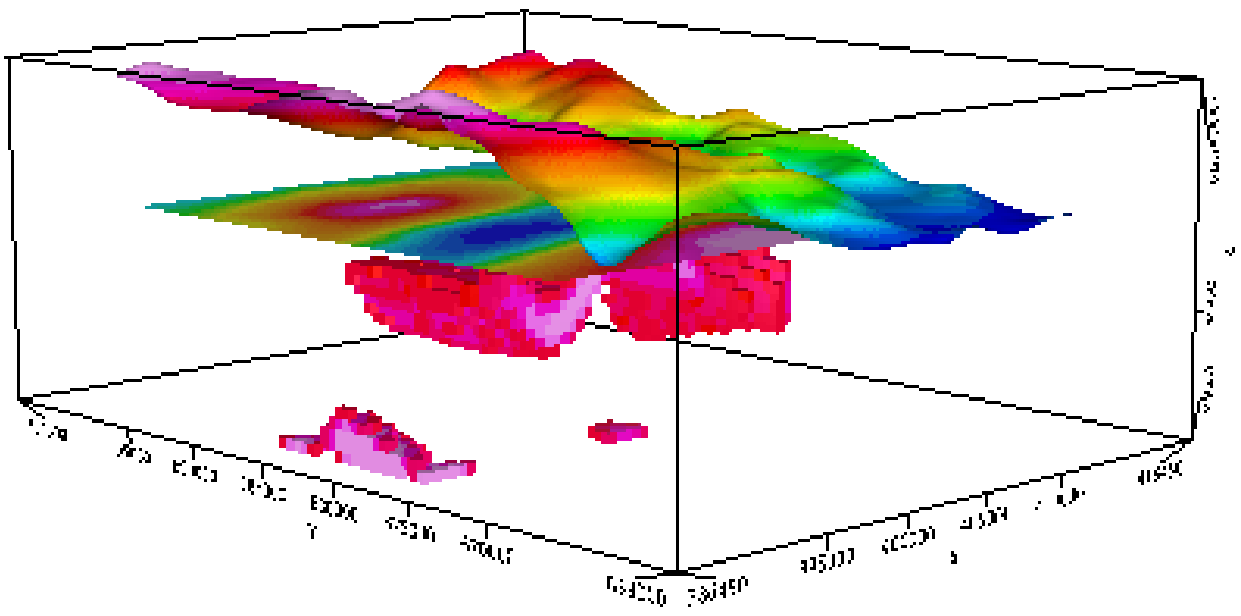

Figure9. Model result overlain by both magnetic data and DEM data

As mentioned earlier, the analytic signal evaluations independently distinguished the Eyigba region as having embedded intrusions (Figure 10). We also observed that the Enyigba region gave higher signal response of up to $0.04 \mathrm{nT} / \mathrm{m}$ on the Analytic Signal map whereas other parts of the study area gave lower signal responses. We propose herewith that the mineral accumulations at this region (as modelled by our 3D results) could be responsible for the relative signal increase. We also observed a higher signal response at locations away from the present mining sites. A similar observation could be 
Mapping Geological Structures Controlling Mineralization in Enyigba Area, South Eastern Nigeria, using Magnetic Inversion Technique

seen on the 3D model results for the region away from the current mining sites. This observation indicates a vast accumulation of the minerals at these locations yet untapped. Inferences drawn from this result indicates vast deposits in the region with greater yield potential. Figure 11 displays the 3D representation of this observation overlaid on the model results. The signal response of the region could clearly be reconciled with the model result from Figure 11.

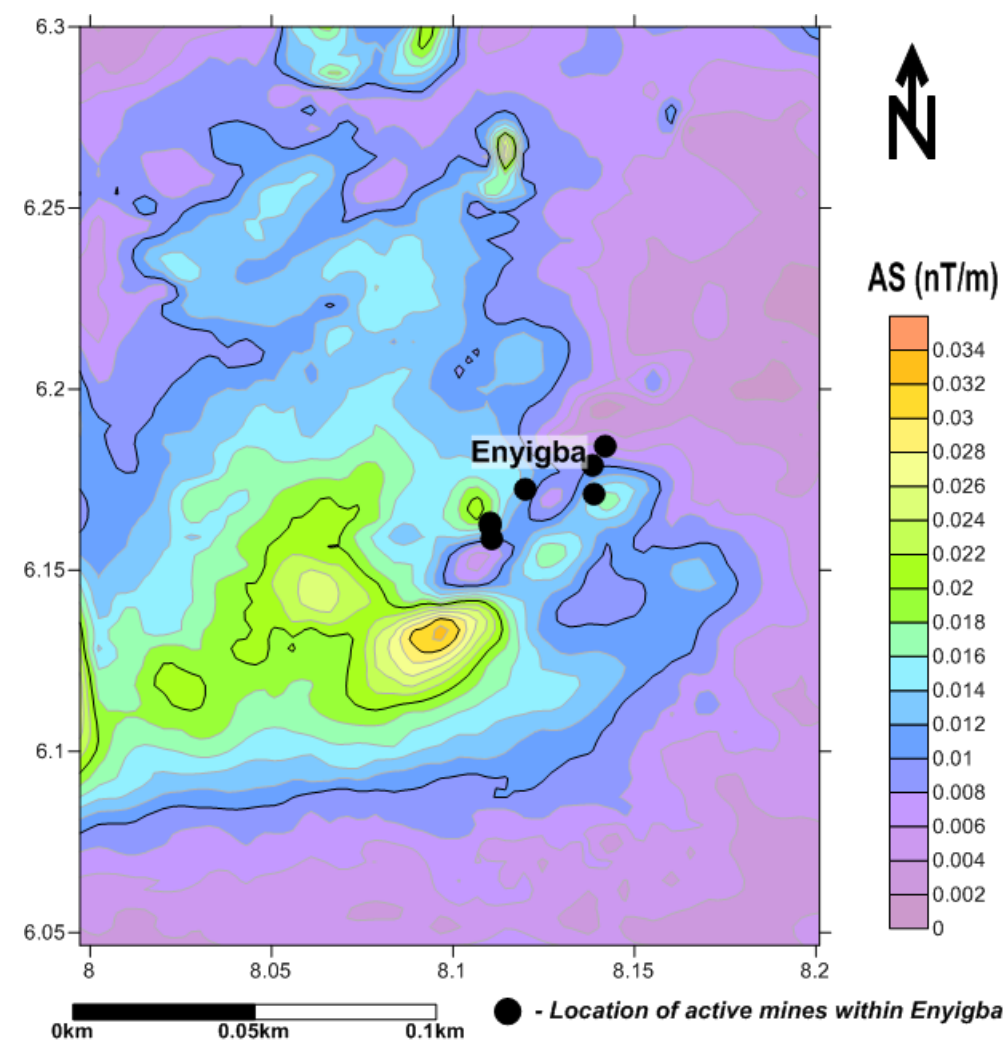

Figure10. Analytic Signal Map of Enyigba and Environs. Black dots represent the currently mined sites in the area. Very strong signal response is observed at the Enyigna region compared to the other parts of the map.

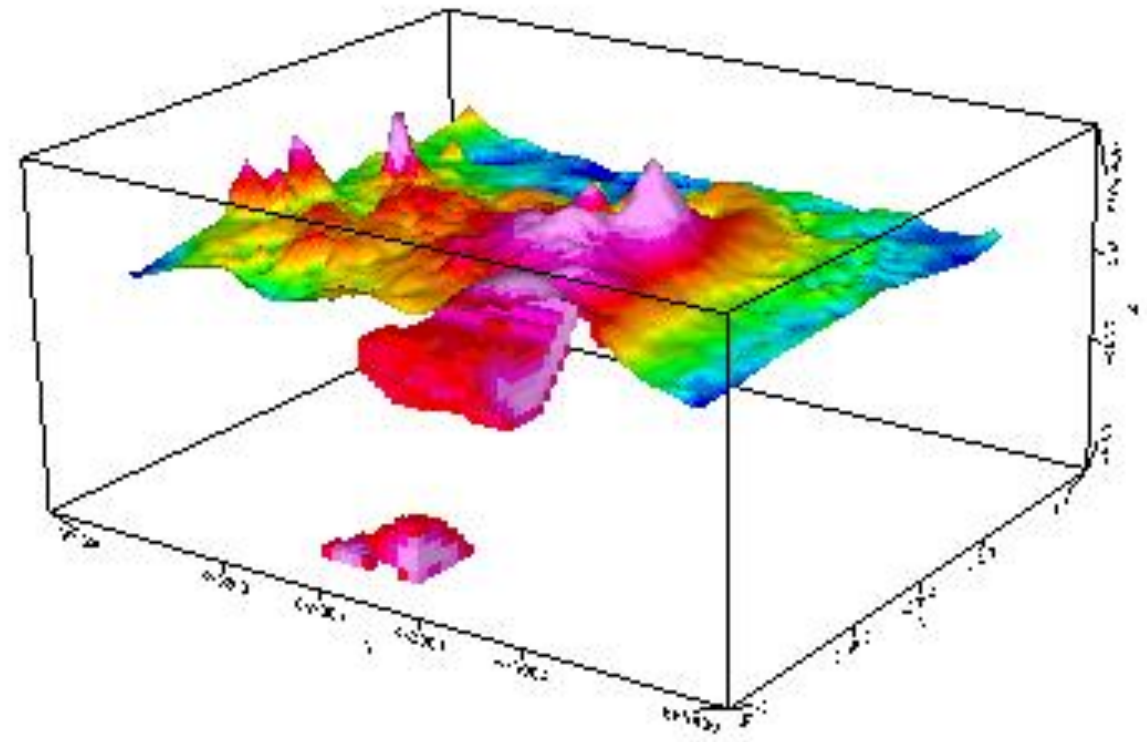

Figure11. 3D Analytic Signal Map of Enyigba and Environs overlaid on the model results. The effect of the accumulated mineral could be seen on the signal response of the Analytic signal map.

\section{CONCLUSION}

Anomalous subsurface bodies in the Enyigba region have been modelled using magnetic field data from the region. Model results have reveal depths to anomalous bodies ranging from $80-400 \mathrm{~m}$. Results also discloses regions around Enyigba with greater deposits and consequently designate this 

using Magnetic Inversion Technique

region as one with greater yield potentials. Some of the current mine locations are yet to access the vast deposits embedded in the region as revealed by our study. An independent examination using the analytic signal technique also maps out the region with significant subsurface anomalies, confirming our 3D modelling results. At the location with vast unexploited deposits, the analytic signal produces spikes of positive signals with higher peaks. The overlaying of results from the 3D and analytic signal evaluation confirms the presence of these depositions in the region. This study presents an outlook on the subsurface mineral deposits/intrusion within the Eyigba region in addition to a revelation of areas with maximum yield potential.

\section{RECOMMENDATION}

We recommend further exploration of the region identified with greater potential than the currently exploited regions. This is necessary for a large scale industrial mining activity. We also recommend application of other geophysical techniques to further analyze, document and confirm results obtained from this study.

\section{ACKNOWLEDGEMENT}

We are grateful to all the anonymous reviewers for their constructive comments which improved the quality of our manuscript. We are also grateful to the Geophysical Research Group of Alex Ekueme Federal University Ndufu Alike Ikwo for their encouragement throughout the course of this research.

\section{REFERENCES}

[1] Abraham, E. M., Lawal, K. M., Ekwe, A. C., Alile, O., Murana, K. A., Lawal, A. A. (2014). Spectral analysis of aeromagnetic data for geothermal energy investigation of Ikogosi Warm Spring - Ekiti State, southwestern Nigeria. Geothermal Energy 2: 1-21.

[2] Burke, K. C., Dessuvagie, T. F. J., Whiteman, A. J. (1970). Geological History of the Benue Valley and Adjacent Areas. In Dessavagie, T.F.J. and Whiteman, A.J. (eds.), 1970, African Geology. University of Ibadan press, $387 \mathrm{pp}$,

[3] Cratchley, C. R., Jones, H. M. (1965). An Interpretation of the Geology and Gravity Anomalies of the Benue Valley, Nigeria. Geographical Journal 132(3): 413.

[4] Fatoye F. B., Ibitomi M. A., Omada J. I. (2014). Lead-Zinc-Barytes mineralization in the Benue Trough. Pelagia Research Library. Advances in Applied Science Research, 5(2):86-92.

[5] Kaliberng, K. (2011). Product Profiles: Lead Ore. http://kaliberexport.blogspot.com/2011/01/productprofileslead-ore.html

[6] Orazulike, D. M. (1994). The Mineralogy and Texture of Lead-zinc-Copper ores of Enyigba lode, Abakaliki, Nigeria. J. Min. Geol 30 (1), 25-32.

[7] Pilkington, M. (2009). 3D magnetic data-space inversion with sparseness constraints. Geophysics 74 (1): P.L7-L15.

[8] Riedel, S. (2008). Airborne-Based geophysical investigation in Dronning Maud land Antarctica. Dissertation, Christian Albrechts Universitat Zu Kiel, Kiel.

[9] Roest, W. R., Verhoef, J., Pilkington, M. (1992). Magnetic interpretation using the 3D analytic signal. Goephysics 57 (1). pp. 116-125

[10] Uzuakpunwa, A. B. (1974). The Abakaliki pyroclastics---easternNigeria: new age and tectonic implications. Geol. Mag. 111, 65-70.

[11] Whitehead, N., Musselman, C. (2005). Montaj Grav/Mag interpretation: Processing, analysis and visualization system for 3D inversion of potential field data for Oasis montaj v6.1. Geosoft Inc. ON, Canada. 
Mapping Geological Structures Controlling Mineralization in Enyigba Area, South Eastern Nigeria, using Magnetic Inversion Technique

\section{AUTHORS' BIOGRAPHY}

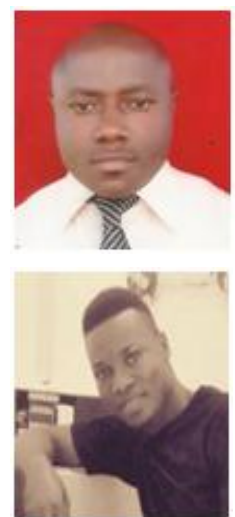

Dr. Ema Abraham, holds a Ph.D. in Geophysics/Exploration Geophysics and currently occupies the Applied Geophysics Programme Coordinator portfolio at Alex Ekwueme Federal University Ndufu Alike Ikwo, Ebonyi State, Nigeria. His research interest includes application of potential fields and seismic methods for petroleum and mineral exploration.

Mr. Daniel Mbara, holds a B.Sc. (Hons) Degree from Geophysics Department of Alex Ekwueme Federal University Ndufu Alike Ikwo, Ebonyi State, Nigeria. He is actively involved in the mining industries and currently a consultant to several solid mineral mining companies.

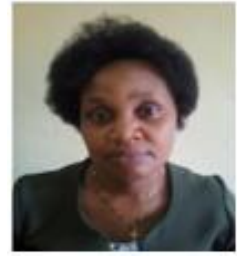

Mrs. Ndidiamaka Eluwa, is a lecturer at Geophysics Department of Alex Ekwueme Federal University Ndufu Alike Ikwo, Ebonyi State, Nigeria. She is currently concluding her research degree (Ph.D.) with specialty in application of potential fields to tackle a broad range of geophysical challenges.

Citation: Ema M. Abraham, et.al (2018). Mapping Geological Structures Controlling Mineralization in Enyigba Area, South Eastern Nigeria, using Magnetic Inversion Technique, International Journal of Mining Science (IJMS), 4(3), pp.31-39, DOI: http://dx.doi.org/10.20431/2454-9460.0403004

Copyright: ( ) 2018 Authors. This is an open-access article distributed under the terms of the Creative Commons Attribution License, which permits unrestricted use, distribution, and reproduction in any medium, provided the original author and source are credited 